\title{
EDITORIAL
}

\section{Home ventilation: need a user support number?}

\author{
P. Delguste and D. Rodenstein
}

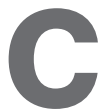
ontemporary homes can include a number of electrical devices aimed at making life easier, such as washing machines, dishwashers and vacuum cleaners. One can also find devices aimed at improving lifestyle, such as exercise bicycles or rowing machines. However, one can also find other types of devices that are aimed at supporting or saving people's life. These can include continuous positive airway pressure machines, home dialysis machines, oxygen concentrators and home respirators. All these devices have electrical plugs, knobs, switches, light bulbs, LEDs and screens. However, the manipulation of these devices is not at all similar, and the interactions between the devices and the users have quite different meanings. Despite the obvious differences between these machines, it remains true that a malfunctioning washing machine or a malfunctioning respirator will require a similar reaction: call the user support number.

Respiratory physicians do not have a long tradition of home life support treatment and every piece of information concerning this issue is worth learning. In the present issue of the European Respiratory Journal, CHATWIN et al. [1] present data on the call centre they established to support more than 1,000 patients on home respirators. The Respiratory Unit of the Royal Brompton Hospital (London, UK) serves a vast geographical area. In order to allow patients to reach them, they established a communication protocol based on telephone numbers patients can call day and night in case they need to or they feel they need to. These calls can be made for a number of reasons; from simple concerns such as asking for spare part replacement, to more disturbing ones such alarms coming on during the night or to a respirator becoming noisy all of a sudden, to very serious ones such as a respirator breakdown in a respirator dependent patient. CHATWIN et al. [1] have recorded and analysed all calls received during a 6-month period, from a population of 1,211 patients, from paediatrics to geriatrics, who were followed up at their centre. All patients had had a training process within the Royal Brompton Hospital unit, and all patients or families were deemed able to understand the use of home respirators, adequately fit and assembly/disassembly the mask and interfaces, start and stop the machines, and even to unlock the settings in order to change them according to telephonic instructions if this was thought useful by the on-call personnel. A personalised information set was delivered to each patient with written

Pneumology Department and Center for Sleep Medicine, Cliniques universitaires Saint Luc, Université catholique de Louvain, Brussels, Belgium.

CORRESPONDENCE: D. Rodenstein, Pneumology Dept and Center for Sleep Medicine, Cliniques universitaires Saint Luc, Université catholique de Louvain, 1200 Brussels, Belgium. E-mail: rodenstein@pneu.ucl.ac.be instructions and information on their respirator, settings and interfaces, spare part numbers, etc.

Given the wide geographic zone covered, the Royal Brompton team seldom, if ever, visit the patients at home. The Royal Brompton unit has a contract with a commercial company to perform the servicing and maintenance of the machines at home. This is done on an annual basis or more frequently if necessary. If the team believes the phone calls are in relation to a machine problem, they refer the case to the Company that visits the patient home within a pre-determined time frame. To this end, all patients are classified in three degrees of dependency on respiratory support, from less than 1 day reserve on spontaneous breathing to 3 days reserve. Patients fully dependent on respiratory support generally have a backup respirator at home. The Company will try to repair the respirator at home if there is a defect, or leave a new respirator with the original settings while the patient's ventilator is taken away for repair. The Company feeds back information to the Royal Brompton unit on a monthly basis.

In order to handle all phone calls from $09.00 \mathrm{~h}$ to $17.00 \mathrm{~h}$ during weekdays, five people with expertise in respiratory support, including one clinical nurse specialist, were backed by two respiratory consultant physicians, two trainee doctors and one administrative coordinator. All other calls were handled by the nursing staff of the Noninvasive Ventilation Ward (Royal Brompton Hospital), composed of four rotating nurses, who could ask advise from another professional with expertise in respiratory support who was on call. These personnel try to solve the problem during the phone call if they deem this possible, or refer the call to the external Company if they believe the respirator is at fault, or refer the patient to the physician in charge if a medical problem is suspected.

During the 6-month period the patients made 528 daytime calls per month, and 14 calls per month were received during the on-call hours from $1 \%$ of the patients. On-call communications were taken from a range of patients according to diagnosis and the degree of dependency. In fact, most calls were made by patients with a low degree of dependency. Despite the written instructions, half of the calls were not urgent and were concerning routine queries or requests for interfaces, whereas the other half of the calls dealt with technical problems with the respirators. Following the phone calls, 188 home visits were necessary from the external Company, mostly for repairs at home or replacement of the default respirator. In 25 visits, no faulty equipment was identified, and 13 of these 25 patients had had a change in their medical condition or required hospital admission. When investigating respirator breakdowns, CHATWIN et al. [1] found an increased malfunction rate 
in older respirators that had served for $>8 \mathrm{yrs}$, as well as in new respirators on the market. There was also a high breakdown rate in highly dependent patients who used respirators for $>16 \mathrm{~h}$ per day.

Many of the characteristics of the system implemented by CHATwIN et al. [1] depend on their particular practice, with a large geographic area to cover. In other circumstances, as is the case in our laboratory, the personnel of the centre could accompany the patients on the first day of home ventilation to verify the placing of the respirator in the bedroom, the availability of electrical connections, the level of autonomy of the patients and family to place the mask interface and so on [2]. If home visits are possible, one would be less prone to allow patients to unlock respirators and change settings on telephonic advice alone; this said, it remains true that everybody interested in home ventilatory support can learn a lot from CHATWIN et al. [1].

The main message seems to be that home ventilation requires a support centre with permanent accessibility, $24 \mathrm{~h}$ per day 365 days per year. Anybody interested in starting a homeventilation programme should include such a call centre among the first steps to be implemented [3]. As stated otherwise, home ventilation should not be performed unless patients have access to a permanent call centre. Handling such a support service requires approxiamately one person per 100 treated patients. This support centre should be coupled with a visiting service that can, upon request from the call centre, rapidly reach the patients house and perform repairs, spare part replacement, respirator replacements, etc. [4]. The details of the organisation can be adapted to the particular situation of a given respiratory unit, but the general framework of permanent accessibility for information on the one hand and maintenance on the other should be respected [5].

There are other things to be learnt from the article by CHATwIN et al. [1]. It seems that however hard one tries to train patients, families and caregivers, however hard one instructs them and supports them with written material and refreshing "courses", many patients will show a candid level of ignorance, forgetfulness or negligence concerning their disease and their respirators. Therefore, the personnel ascribed to the call centre should be prepared to receive many non urgent questions and demands that can make it hard to detect the rare patients whose calls are due to a real problem with their equipment or, even worse, to deterioration in their clinical status mistakenly attributed to a failing respirator [6]; especially since most of the calls do not seem to come from the most seriously ill patients but rather from the less dependent ones.

CHATwin et al. [1] were able to identify three characteristics of respirator breakdown: respirators used for $>16 \mathrm{~h}$ per day, respirators that had been used for $>8 \mathrm{yrs}$, and respirators that are new on the market. This is very useful information and allows changes in respirators to be planned well in advance, considers $16 \mathrm{~h}$ a day on a ventilator as complete dependency and delivery of two respirators that can be alternated, calls our attention to refrain from the usual enthusiasm of trying too quickly to get the newest machines, devices and gadgets, and perhaps without due attention to safety, security and robustness. CHATwIN et al. [1] point to the need for a central reporting agency or body to concentrate all this information and react accordingly, if needed. A European agency appears suitable for such a role; such as already exists for pharmaceutical products [7].

CHATwIN et al. [1] express hope that telemonitoring will improve the situation, and will allow for more preventive steps to be taken before problems arise. We are sympathetic to the hope, but we are also cautious and would like to see experimental data showing what the exact added value of telemonitoring systems is for patients on home respirators. What will certainly change in the near future is that a primary telephonic service (the patient call centre) will evolve towards a web-based platform with $24 \mathrm{~h}$ a day 365 days per year availability. Support personnel will have to type fast and well! This change may help to more easily identify (and adequately respond to) urgent messages from the routine messages.

Some readers might be surprised to learn that the population described in this report includes patients with sleep apnoea needing two-level pressure treatment rather than continuous positive airway pressure, or many patients with chronic obstructive pulmonary disease, a still as yet not evidencebased recognised disease for noninvasive ventilation therapy [8]. Others may be surprised by the extremely low number of patients on volumetric respirators. Nevertheless, those are minor details and should not detract us from appreciating the great amount of useful information contained in the study by CHATWIN et al. [1], which represents a major step forward towards the establishment of a much needed quality-control system in Europe [9].

\section{STATEMENT OF INTEREST}

None declared.

\section{REFERENCES}

1 Chatwin M, Heather S, Hanak A, et al. Analysis of home support and ventilator malfunction in 1,211 ventilator-dependent patients. Eur Respir J 2010; 35: 310-316.

2 Delguste P, Rodenstein D. Implementation and monitoring of mechanical ventilation via nasal access. Eur Respir Rev 1993; 12: 266-269.

3 Donner CF, Polu J-M, Braghiroli A, et al. Home respiratory assistance network. In: Muir J-F, Ambrosino N, Simmonds AK, eds. Noninvasive Mechanical Ventilation. Eur Respir Mon 2001; 16: 281-292.

4 Tearl DK, Cox TJ, Hertzog JH. Hospital discharge of respiratorytechnology-dependent children: role of a dedicated respiratory car discharge coordinator. Respir Care 2006; 51: 744-749.

5 Simonds AK. Discharging the ventilator dependent patient. In: Muir J-F, Ambrosino N, Simmonds AK, eds. Noninvasive Mechanical Ventilation. Eur Respir Mon 2001; 16: 137-146.

6 Jardine E, Wallis C. Care guidelines for the discharge home of the child on long term assisted ventilation in the United Kingdom. Thorax 1998; 53: 762-767.

7 Farre R, Lloyd-Owen SJ, Ambrosino N, et al. Quality control of equipment in home mechanical ventilation: a European survey. Eur Respir J 2005; 26: 86-94.

8 Wijkstra PPJ, Lacasse Y, Guyatt GH, et al. Nocturnal non-invasive positive pressure ventilation for stable chronic obstructive pulmonary disease. Cochrane Database Syst Rev 2002; 3: CD002878.

9 Farre R, Navajas D. Quality control: a necessary, but sometimes overlooked, tool for improving respiratory medicine. Eur Respir J 2009; 33: 722-723. 